\title{
Primary culture of intestinal epithelial cells as a potential model for Toxoplasma gondii enteric cycle studies
}

\author{
Marcos de Assis Moura', Maria Regina Reis Amendoeira², Helene Santos Barbosa1/+ \\ ${ }^{1}$ Laboratório de Biologia Estrutural ²Laboratório de Toxoplasmose, Instituto Oswaldo Cruz-Fiocruz, Av. Brasil 4365, 21040-361 \\ Rio de Janeiro, RJ, Brasil
}

\begin{abstract}
The primary culture of intestinal epithelial cells from domestic cats is an efficient cellular model to study the enteric cycle of Toxoplasma gondii in a definitive host. The parasite-host cell ratio can be pointed out as a decisive factor that determines the intracellular fate of bradyzoites forms. The development of the syncytial-like forms of $\mathrm{T}$. gondii was observed using the 1:20 bradyzoite-host cell ratio, resulting in similar forms described in in vivo systems. This alternative study potentially opens up the field for investigation into the molecular aspects of this interaction. This can contribute to the development of new strategies for intervention of a main route by which toxoplasmosis spreads.
\end{abstract}

Key words: Toxoplasma gondii - cat enteric cycle of $T$. gondii - intestinal epithelial cells - primary culture of enterocytes

Toxoplasma gondii, the aetiological agent of toxoplasmosis, is an obligatory intracellular parasite, one of the most common zoonoses in the world. The wide distribution of the parasite is due to its multiple mechanisms of transmission: ingestion of cysts present in raw or poorly cooked meat; ingestion of oocysts in faeces of Felidae that contaminate food, water and soil (Dubey \& Shen 1991, Uchoa et al. 1999, Dubey et al. 2004); by tachyzoite infection through vertical transmission during ingestion of milk in a breast-fed infant whose mother acquired a primary infection with $T$. gondii or horizontal transmission by ingestion of any type of milk which is a potential source of infection, in particular if consumed raw (Tenter 2009). The transmission cycle is demonstrated in Fig. 1.

Approximately $25 \%$ of the human population is chronically infected (Black \& Boothroyd 2000). The infection has clinical importance in two situations: (i) in congenital toxoplasmosis, where it can cause severe damage to the embryo in the form of mental retardation and blindness and (ii) as an opportunist infection in immunocompromised patients, inducing encephalic toxoplasmosis, which can be fatal (Dubey 2002, Hill \& Dubey, 2002).

On the 100th anniversary of the discovery of the parasite $T$. gondii, the literature presents a large number of scientific articles addressing such topics as toxoplasmosis (16,306 articles), $T$. gondii (9,659 articles) and infective stages: tachyzoite (1,106 articles), bradyzoite (262 articles) and oocysts (493 articles). Note, however, that the specific knowledge of the enteric cycle of $T$. gondii in Felidae is limited to 17 articles and is restricted to four articles in relation to the morphological characterisation in vivo (Frenkel et al. 1970, Dubey \& Frenkel

\footnotetext{
Financial support: CNPq, CAPES, PAPES-Fiocruz, FAPERJ

+ Corresponding author: helene@ioc.fiocruz.br

Received 23 June 2009

Accepted 27 August 2009
}

1972, Fergunson 2004, Speer \& Dubey 2005). The lack of cellular models that allow the reproduction of the enteric cycle of $T$. gondii exclusive of the definitive host has contributed to this picture. An alternative model to study the sexual cycle of $T$. gondii is the introduction of primary cultures of cat enterocytes.

After ingestion of the tissue cysts by the definite host, the cyst wall is destroyed by proteolytic enzymes of the stomach and intestine, releasing the bradyzoites, which then penetrate the intestinal cells and begin the development of some generations of $T$. gondii (Dubey \& Frenkel 1972). Five distinct morphological types, enteroepithelial stages or schizonts of T. gondii (types A, B, C, D and E) occur only in felines, the definite hosts, and involve the schizogony, gametogony and sporogony processes, resulting in the formation of immature oocysts (Dubey \& Frenkel 1972, 1973, Dubey 1973, Dubey et al. 2004).

The schizonts multiply exclusively in the superficial enterocytes of the small gut, giving origin to the merozoites, before the beginning of gametogenesis (Dubey \& Frenkel 1972, Frenkel \& Dubey 1972). The microgametes are then liberated in the small gut and are attracted to the macrogamonts. The immature oocyst is formed in the intestinal epithelium of felines and eliminated, still immature, together with faeces into the environment. The mature oocysts are formed by sporogony, a process that occurs outside the host and leads to the development of infectious oocysts, which contain two sporocysts, each containing four sporozoites (Dubey \& Frenkel 1973) (Fig. 2).

The morphologic and molecular characterisation of the enteroepithelial stages of $T$. gondii, including the sexual cycle, described thus far was realised in in vivo studies, using domestic feline neonates (Dubey \& Frenkel 1972, Ferguson et al. 1974, 1975, Koyama et al. 2000, Ferguson 2004, Speer \& Dubey 2005). The present study is a pioneering work showing the development of $T$. gondii schizonts in vitro similar to what has been previously described in vivo.

Primary cultures of feline intestinal epithelial cells were obtained from the foetus of a clinically healthy 


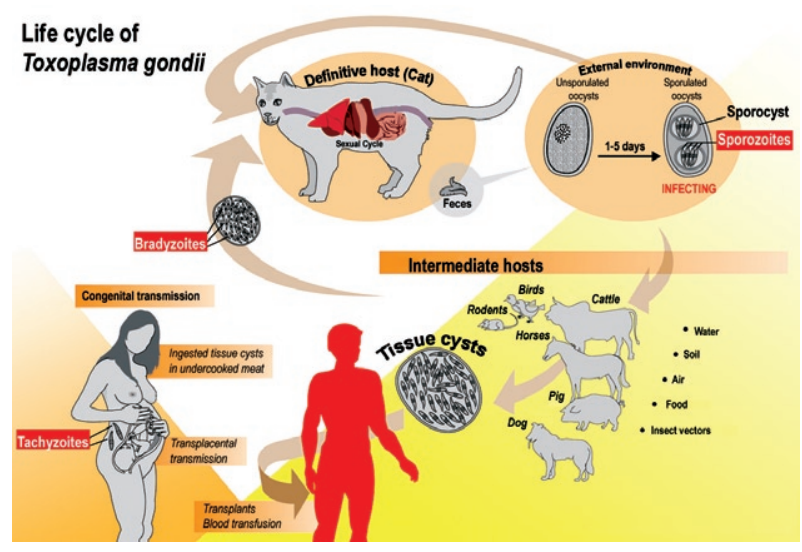

Fig. 1: life cycle of $T$. gondii showing the routes of transmission between intermediate and definitive hosts. Schematic created by MA Moura and HS Barbosa.

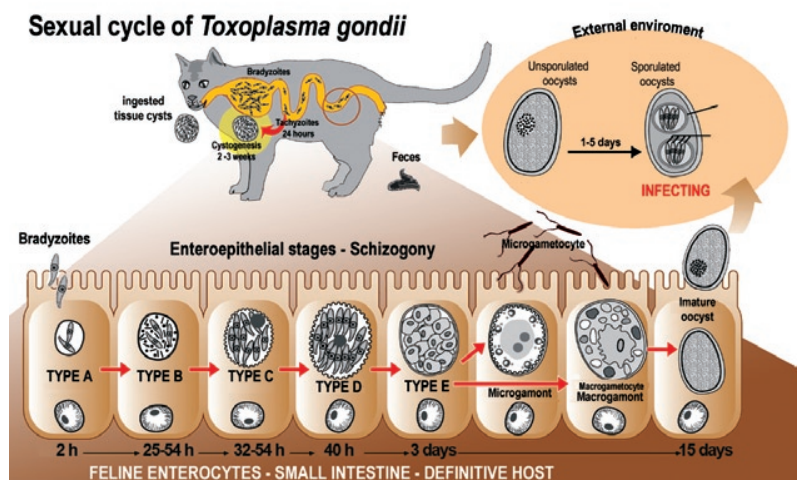

Fig. 2: enteroepithelial stage of $T$. gondii in surface epithelial cells of the small intestine from a domestic cat. Schematic created by MA Moura and HS Barbosa based mainly on papers from Fergunson (2004) and Speer and Dubey (2005).

pregnant domestic cat (no gastrointestinal disease and serologically negative for $T$. gondii, feline immunodeficiency virus and feline leukaemia virus). The samples of small intestine were collected aseptically corresponding to the jejunum-ileum region. The fragments were placed in nonenzymatic dissociation buffer ( $\mathrm{pH}$ 7.2) containing $1 \mathrm{mM}$ EDTA, 1mM EGTA, $0.5 \mathrm{mM}$ dithiothreitol and $10 \%$ antibiotic solution for 20 min under agitation at RT (Perreault \& Jean-Francois 1996, Macartney et al. 2000, Aldhous et al. 2001, Rusu et al. 2005). The cell aggregates were plated in DMEM/Hams medium [Dulbecco's Modified Eagle's Medium/Hams Nutrient F12 (1:1)] containing $10 \%$ antibiotic solution, $1 \mathrm{mM}$ glutamine, $10 \%$ bovine foetal serum and $20 \mathrm{ng} / \mathrm{mL}$ epidermal growth factor (Sanderson et al. 1996, Aldhous et al. 2001). The cultures were incubated at $37^{\circ} \mathrm{C}$ in a $5 \% \mathrm{CO}_{2}$ atmosphere and the medium was renewed every two days.

The use of bradyzoites of $T$. gondii (Guimarães et al. 2008) to infect feline intestinal epithelial cells is justified because it represents the major route of parasite transmission, through the consumption of raw meat by animals or humans. Another prominent point of this paper is the introduction of feline cells for the first time as a cell model to study the $T$. gondii-host cell interaction.

Our results point out that the intracellular fate of the parasite is dependent on the parasite-host cell ratio employing ME49 strain bradyzoites: (i) the development of the lytic cycle of the parasite, using the 1:5 parasite-host cell ratio, with conversion of bradyzoites in tachyzoites, culminating with their intense proliferation and rosette formations (Fig. 3A); (ii) maintenance and establishment of bradyzoites with the formation of cysts, using a 1:10 bradyzoite-host cell ratio (Fig. 3B) and (iii) the development of the syncytial-like forms of T. gondii (Fig. 3C), using using the ratio of 1:20 (bradyzoite per host cell), similar to those forms described in vivo. Our results also showed that the reduction of the 1:10 bradyzoite-host cell ratio leads to the spontaneous formation of intracellular cysts, without any physical, chemical or immunological modulation. These data introduce new biological aspects of $T$. gondii host cell interaction.

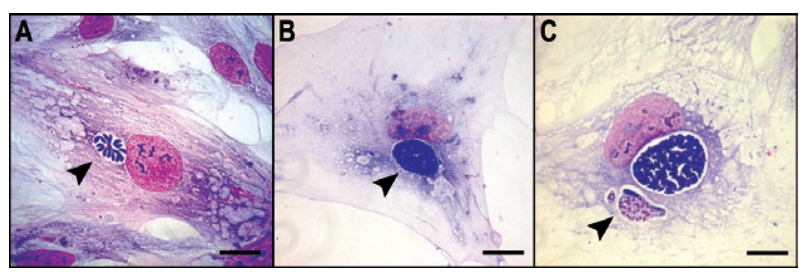

Fig. 3: light microscopy of feline enterocytes infected with bradyzoites of Toxoplasma gondii stained by Giemsa. A: two hours of infection (1:5 parasite/host cells ratio). The lytic cycle is induced with rosette formations (arrowhead); B: six hours of infection (1:10 parasite/host cells ratio), showing cyst-like structures (arrowhead); C: six hours of infection (1:20 parasite/host cells ratio). Parasitophorous vacuole containing syncytial-like forms $(\mathrm{Bar}=20 \mu \mathrm{m})$.

The experimental strategies implemented in the present work reproduced in vitro the natural microenvironment established during enteric development of $T$. gondii in the definitive host, the domestic cat. The introduction of the feline epithelial intestinal cell (FEIC) as a cellular model shows that it can potentially contribute to new approaches to investigating the cell biology of the parasite. Also, FEIC is an alternative methodology to better understanding the enteric cycle of T. gondii under controlled conditions, opening up the field for investigation of the molecular aspects of this interaction and contributing, for example, to the development of new strategies aimed at intervention in one of the main routes by which toxoplasmosis spreads.

\section{ACKNOWLEDGMENTS}

To Marielle Delfin Pereira and Sandra Maria de Oliveira Souza, for their technical assistance, and to David Straker, for the English revision. 


\section{REFERENCES}

Aldhous MC, Shmakov AN, Bode J, Ghosh S 2001. Characterization of conditions for the primary culture of human small intestinal epithelial cells. Clin Exp Immunol 125: 32-40.

Black MW, Boothroyd JC 2000. Lytic cycle of Toxoplasma gondii. Microbiol Mol Biol Rev 64: 607-623.

Dubey JP 1973. Feline toxoplasmosis and coccidiosis: a survey of domiciled and stray cats. J Am Vet Med Assoc 162: 873-877.

Dubey JP 2002. Tachyzoite-induced life cycle of Toxoplasma gondii in cats. J Parasitol 88: 713-717.

Dubey JP, Frenkel JK 1972. Cyst-induced toxoplasmosis in cats. J Protozool 19: 155-177.

Dubey JP, Frenkel JK 1973. Experimental toxoplasma infection in mice with strains producing oocysts. J Parasitol 59: 505-512.

Dubey JP, Navarro IT, Sreekumar C, Dahl E, Freire RL, Kawabata HH, Vianna, MC, Kwok OC, Shen SK, Thulliez P, Lehmann T 2004. Toxoplasma gondii infections in cats from Parana, Brazil: seroprevalence, tissue distribution and biologic and genetic characterization of isolates. J Parasitol 90: 721-726.

Dubey JP, Shen SK 1991. Rat model of congenital toxoplasmosis. Infect Immun 59: 3301-3302.

Ferguson DJ 2004. Use of molecular and ultrastructural markers to evaluate stage conversion of Toxoplasma gondii in both the intermediate and definitive host. Int J Parasitol 34: 347-360.

Ferguson DJ, Hutchison WM, Dunachie JF, Siim JC 1974. Ultrastructural study of early stages of asexual multiplication and microgametogony of Toxoplasma gondii in the small intestine of the cat. Acta Pathol Microbiol Scand B Microbiol Immunol 82: 167-181.

Ferguson DJ, Hutchison WM, Siim JC 1975. The ultrastructural development of the macrogamete and formation of the oocyst wall of Toxoplasma gondii. Acta Pathol Microbiol Scand B 83: 491-505.

Frenkel JK, Dubey JP 1972. Toxoplasmosis and its prevention in cats and man. J Infect Dis 126: 664-673.
Frenkel JK, Dubey JP, Miller NL 1970. Toxoplasma gondii in cats: fecal stages identified as coccidian oocysts. Science 167: 893-896.

Guimarães EV, De Carvalho L, Barbosa HS 2008. Primary culture of skeletal muscle cells as a model for studies of Toxoplasma gondii cystogenesis. J Parasitol 94: 72-83.

Hill D, Dubey JP 2002. Toxoplasma gondii: transmission, diagnosis and prevention. Clin Microbiol Infect 8: 634-640.

Koyama T, Shimada S, Ohsawa T, Omata Y, Xuan X, Inoue N, Mikami T, Saito A 2000. Antigens expressed in feline enteroepithelial-stages parasites of Toxoplasma gondii. J Vet Med Sci 62: 1089-1092.

Macartney KK, Baumgart DC, Carding SR, Brubaker JO, Offit PA 2000. Primary murine small intestinal epithelial cells, maintained in long-term culture, are susceptible to rotavirus infection. J Virol 74: 5597-5603.

Perreault N, Jean-Francois B 1996. Use of the dissociating enzyme thermolysin to generate viable human normal intestinal epithelial cell cultures. Exp Cell Res 224: 354-64.

Rusu D, Loret S, Peulen O, Mainil J, Dandrifosse G 2005. Immunochemical, biomolecular and biochemical characterization of bovine epithelial intestinal primocultures. BMC Cell Biol 6: 42.

Sanderson IR, Ezzell RM, Kedinger M, Erlanger M, Xu ZX, Pringault E, Leon-Robine S, Louvard D, Walker WA 1996. Human fetal enterocytes in vitro: modulation of the phenotype by extracellular matrix. Proc Natl Acad Sci USA 93: 7717-7722.

Speer CA, Dubey JP 2005. Ultrastructural differentiation of Toxoplasma gondii schizonts (types B to E) and gamonts in the intestines of cats fed bradyzoites. Int J Parasitol 35: 193-206.

Tenter AM 2009. Toxoplasma gondii in animals used for human consumption. Mem Inst Oswaldo Cruz 104: 364-369.

Uchoa CM, Duate R, Laurentino-Silva V, Alexandre GM, Ferreira HG, Amendoeira MRR 1999. Standardization of enzyme-linked immunosorbent assay ELISA to detect anti-Toxoplasma gondii IgM and IgG antibodies, and comparison with the indirect immunofluorescence technique. Rev Soc Bras Med Trop 32: 661-669. 